\title{
Hepatoprotective assessment of lyophilized neem leaf powder against carbon tetrachloride induced liver toxicity in albino rats
}

\section{Ravindranath H. Aladakatti and MukhtarAhmed G. Ghodesawar}

\begin{abstract}
In view of medicinal utilities of neem plant have been described especially for in ayurvedic remedy for alleviating of liver disorders, the present study was designed to evaluate the evidence of acute toxicity of lyophilized neem leaf powder (LNLP) and its preventive effects against carbon tetrachloride $\left(\mathrm{CCl}_{4}\right)$ induced hepatotoxicity in rats. Group allocation in hepatoprotective activity study included vehicle, $\mathrm{CCl}_{4}(1 \mathrm{ml} / \mathrm{kg})$, Silymarin $(100 \mu \mathrm{g} / \mathrm{kg} /$ day $)+$ $\mathrm{CCl}_{4}$ and graded doses of LNLP (50 and $100 \mathrm{mg} / \mathrm{kg}$, BW/ day) + $\mathrm{CCl}_{4}$. On 9th day, blood was obtained for determination of biochemical parameters and liver tissue for pathological examination. There were no toxicological effects as evidenced by indications of mortality, behavior, diet consumption and tissue weights, though, some hematological parameters showed variations in their value at higher dose level. The level of protection was deliberated by using various biochemical parameters like total protein, albumin, BUN, AST, ALT and ALP levels. LNLP showed dose dependent hepatoprotective in nature which was further validated by marked diminish in occurrence of hepatocellular necrosis on histopathological analysis. This study suggests LNLP possess hepatoprotective effect against $\mathrm{CCl}_{4}$ induced liver damage in rats with efficiency similar to standard drug and possible mechanism behind the results is discussed.
\end{abstract}

Keywords: LNLP, Acute Toxicity, $\mathrm{CCl}_{4}$, Hepatoprotection, Silymarin

Ravindranath H. Aladakatti

Central Animal Facility, Indian Institute of Science, Bengaluru-

560012, Karnataka (India)

MukhtarAhmed G. Ghodesawar

Department of Zoology, Anjuman Arts, Sciences and Commerce

College, 586101 Vijapura, Karnataka (India)

\section{Introduction}

A variety of medicinal plants have been extensively used in the traditional system of medicine for the management of liver disorder. The employ of natural remedies for the healing of liver diseases has a long history and medicinal plants and their derivatives are still used all over the world in one form or the other for this purpose. These herbal drugs have shown the ability to maintain the normal functional statues of the liver with or without fewer side effects. Indian neem tree Azadirachta indica (Syn: Melia azadirach: Meliaceae) has great reputation in Ayurvedic medicine for treatment of liver disorders. The medicinal utilities have been described and studies on different parts of this plant have been shown to be hepatoprotective nature against liver damage when toxic agents were used (Chattopadhyay et al., 1992; Khatkar et al., 2010; Baligar et al., 2014a, b).

From the literature, the herbal hepatoprotective have not as much of side effect or interaction as contrast to synthetic drug but in other hand scientific facts from experiments done to assess the safety and efficiency of traditional these medicine products and practices is limited. Consequently, it was found worthwhile to examine the acute toxicity and hepatoprotective nature of neem lyophilized leaf powder (LNLP) in order to establish its potential use. This study deals first with acute toxicity including feed and water consumption, individual BWs, cage side observations, relative organ weight analysis, hematological analysis and; second one is to evaluate the other biochemical parameters and histopathological changes against $\mathrm{CCl}_{4}$ induced hepatic damage in rats with a view to clarify probable mechanism following its hepatoprotective action albino rats.

\section{Materials and Methods}

\section{Preparation of lyophilized neem leaf powder (LNLP)}

An aqueous extract was prepared from neem leaves. Neem leaves were ground in a mixer and filtered with gauze. The filtrate was washed with chloroform in 1:1 proportion, centrifuged at 3000 $\mathrm{rpm}$ for $20 \mathrm{~min}$. The pellet was discarded and the supernatant frozen at $-20^{\circ} \mathrm{C}$ for lyophilization. The extracts were lyophilized separately.

\section{Chemicals and Reagents}

Carbon tetrachloride used was of analytical grade and procured from E. Merck (India) Ltd. Mumbai; Silymarin was procured from M/s Micro Labs, Bengaluru. All other solvents and chemicals were of analytical grade and purchased from local commercial sources.

\section{Animals}

Wistar albino rats weighing 200-220g of either sex were obtained from the rat colony maintained in the department and were acclimatized for 10 days under standard housing conditions $\left(26^{\circ} \pm 2^{\circ} \mathrm{C} ; 45-55 \% \mathrm{RH}\right.$ with $12: 12 \mathrm{~h}$ light/dark cycle). The animals were maintained on a standard diet and water was given ad libitum and habituated to laboratory conditions for $48 \mathrm{~h}$ prior to the experimental protocol to minimize any non-specific stress. The animals were maintained under standard conditions in the animal house approved by Committee for the Purpose of Control and Supervision on Experiments on Animals (CPCSEA) and necessary approval from the Institutional Animal Ethics Committee (IAEC) was obtained before undertaking animal experimentation.

\section{Acute Toxicity Studies}

Acute oral toxicity study was performed as per OECD-404 guidelines (1987). 10 rats/group (5 males and 5 females) were used for the study. Group 1 was control group and other groups were that of LNLP at different doses $(250,500$ and $1000 \mathrm{mg} / \mathrm{kg} \mathrm{BW}$, respectively). Single dose of the LNLP was separately administrated orally to each animal. Signs of toxicity, feed and water consumption of each animal was observed for 14 days. Individual animal BW was recorded on day one and at the end of experiment.

\section{Cage side observations}

In acute toxicity study, the animals were observed prior to dosing. Thereafter, observations were made at every hour, for five hours and then at $24 \mathrm{~h}$ and then every day for 14 days. All observations were systematically recorded, with individual records being maintained for each animal. Cage side observations included 
the evaluation of skin and fur; eyes; respiratory effect; autonomic effects, such as salivation, diarrhea, urination; and central nervous system effects, including tremors and convulsions, straub tail, relaxation, changes in the level of activity, gait and posture, reactivity to handling, altered strength and stereotypy (Nair et al., 2009).

\section{Relative organ weight (ROW) analysis}

Heart, liver, brain, kidneys, lungs, thymus glands, spleen, adrenal glands, testes and uterus were mopped with filter paper, weighed and the relative weights were calculated and expressed as $\mathrm{g} / 100 \mathrm{~g} \mathrm{BW}$.

$$
\text { ROW }=\frac{\text { Absolute organ weight }(\mathrm{g})}{\text { BW of rats on sacrifice day }(\mathrm{g})} \times 100
$$

\section{Hematological analysis}

At the end of study, all animals were fasted for $12 \mathrm{~h}$ and then under mild ether anesthesia, animals were sacrificed and blood samples were collected. Blood was collected immediately into tubes containing EDTA for analysis of hematological parameters viz. hemoglobin, total red blood cells (RBC), packed cell volume, mean corpuscular volume (MCV), mean corpuscular hemoglobin $(\mathrm{MCH})$, mean corpuscular hemoglobin concentration (MCHC), total white blood cells (WBC), neutrophils, lymphocytes, eosinophils, monocytes, basophiles, total platelet count (Theml et al., 2004) using automated hematology analyzer (Sysmex KX-21, Japan).

\section{Assessment of Hepatoprotective activity}

LNLP did not produce any mortality up to a dose of (1000 $\mu \mathrm{g} / \mathrm{kg}$, po $)$. Hence $1 / 20^{\text {th }}(50 \mathrm{mg} / \mathrm{kg}$, po $)$ and $1 / 10^{\text {th }}(100 \mathrm{mg} / \mathrm{kg}$, po $)$ of these doses were employed for further experimental pharmacological investigations.

\section{Hepatoprotective role of $\mathrm{LNLP}$ in $\mathrm{CCl}_{4}$ induced hepatotoxicity}

To study the $\mathrm{CCl}_{4}$ induced hepatic injury in rats, $\mathrm{CCl}_{4}$ was diluted with liquid paraffin (1:1) before intra-peritoneal administration. The animals were divided into following 5 groups. Group 1: Vehicle (50\% aqueous sucrose solution) for 9 days; Group 2: Vehicle $+\mathrm{CCl}_{4}(1 \mathrm{ml} / \mathrm{kg})$ on ninth day. Group 3: Silymarin (100 $\mu \mathrm{g} / \mathrm{kg} / \mathrm{day}, \mathrm{po})+\mathrm{CCl}_{4}(1 \mathrm{ml} / \mathrm{kg}$, po) on ninth day; and Groups 4 and 5: LNLP (50 and $100 \mathrm{mg} / \mathrm{kg} / \mathrm{day}$, po) $+\mathrm{CCl}_{4}(1 \mathrm{ml} / \mathrm{kg}$, po) respectively on ninth day. To enhance the acute liver damage in animals of groups 2, 3, 4 and 5 , food was withdrawn $12 \mathrm{~h}$ before $\mathrm{CCl}_{4}$ administration. Animals were sacrificed $24 \mathrm{~h}$ after administration of $\mathrm{CCl}_{4}$. Blood samples were collected by puncturing the retro-orbital plexus under light ether anesthesia and allowed to coagulate for $30 \mathrm{~min}$ at $37^{\circ} \mathrm{C}$. Serum was separated by centrifugation at $2500 \mathrm{rpm}$ at $37^{\circ} \mathrm{C}$ for $15 \mathrm{~min}$ and analyzed for various biochemical parameters. The liver was removed after sacrifice and observed for weight, volume and appearance, washed with normal and then fixed in $10 \%$ formalin for histopathological studies (Matsuda et al., 1991).

\section{Serum Biochemical analysis}

Hepatoprotective effect of LNLP was evaluated by the assay of liver function serum biochemical parameters according to standard methods by using test kit (Span Diagnostics Ltd.) and were analyzed at the end of the study using autoanalyzer (Erba Chem-7, Germany). Estimation of serum total protein content by modified Biuret method (Yatzidis, 1977); serum albumin by the method given by Corcoran and Durnan (1977); serum blood urea nitrogen (BUN) by Enzymatic Urease (Berthelot) method (Fawcett and Scott, 1960); alkaline phosphatase (ALP) activity by the method of Kind and King (1954); aspartate aminotransferase (AST) and alanine aminotransferase (ALT) activities by the method of Reitman and Frankel (1957).

\section{Light microscopy analysis}

Animals were sacrificed and the abdomen was cut open to remove the liver. The liver was observed for weight (LW), volume (LV) and appearance. The liver was washed with normal saline and fixed in Bouin's solution (mixture of $75 \mathrm{ml}$ of saturated picric acid, 25 $\mathrm{ml}$ of $40 \%$ formaldehyde and $5 \mathrm{ml}$ of glacial acetic acid) for $12 \mathrm{~h}$, then embedded in paraffin using conventional methods (Galigher and Kozloff, 1971) and cut into $5 \mu \mathrm{m}$ thick sections and stained using haematoxylin-eosin dye and finally mounted in di-phenyl xylene. The sections were observed under light microscope for histopathological changes.

\section{Statistical analysis}

Data were analyzed using one way analysis of variance (ANOVA) using the Graph Pad Prism software method, followed by either Dunnet test or Turkey's multiple comparison tests by comparing all treated groups against controls. Values represented are mean \pm SEM $(n=5) . P \leq 0.05$ is considered to indicate a significant difference between experimental and controls.

\section{Results}

\section{Acute toxicity study}

In acute toxicity study, no adverse reactions or behavioral changes were observed after each graded doses of administration of LNLP during the whole period of experimentation. No considerable changes in general feed and water consumption rates suggesting that this LNLP had no effect on normal growth of rats. However, there was little alteration at higher dose level groups, but not significant, in the BW (Fig.1A \& B) and relative weight (Fig. 2A \& B) of few organs of both either sexes $(\mathrm{P} \leq 0.05)$ during experimental period.

\section{Hematological parameters}

The hematological parameters of male and female rats were shown in Figs.3 (A-K) \& 4(A-K) respectively. Considerable difference $(\mathrm{P} \leq 0.05)$ in some hematological parameters of both sexes, however, at the lower dose levels, both of either sex exhibited the variation in the some of the parameters, but the difference was insignificant against the control.

\section{Biochemical parameters}

Pretreatment with LNLP at the dose levels of 50 and $100 \mathrm{mg} / \mathrm{kg}$ $\mathrm{BW}$ appreciably controlled the change in the biochemical parameters compared to control and the effect was similar to that of standard drug. A marked decrease $(\mathrm{P} \leq 0.05)$ in the levels of total protein (Fig.5A) and albumin (Fig.5B), sign of elevated $(\mathrm{P} \leq 0.05)$ in the levels of BUN (Fig.5C), ALP (Fig.5D) and hepato specific enzymes like AST (Fig.5E) and ALT (Fig.5F) in $\mathrm{CCl}_{4}$-induced group when compared to normal controls. Further, at higher dose level, the recovery towards normalization in these levels was similar to that of standard, however, at lower dose level, this active constituent did not have protective effects. 
Proc. of the Seventh International Conference On Advances in Applied Science and Environmental Engineering - ASEE 2017. Copyright ( $)$ Institute of Research Engineers and Doctors. All rights reserved.

ISBN: 978-1-63248-125-2 doi: 10.15224/ 978-1-63248-125-2-02

\section{Histopathology}

The histological alterations allied with the hepatoprotective activity in LNLP pretreated rats on the whole supported the evaluation of the serum enzyme activities. Liver sections from control rats showed normal lobular architecture and normal hepatic cells with a well preserved cytoplasm and well-defined nucleus and nucleoli (Fig.6A). In $\mathrm{CCl}_{4}$ treated animals, the liver pathological changes were characterized by severe hepatocellular degeneration, necrosis (arrow head) and congestion of sinusoids (arrows) along with periportal mononuclear cell infiltration due to $\mathrm{CCl}_{4}$ toxicity (Fig.6B). These histopathological alterations were remarkably reversed in graded doses of LNLP pretreated rats with lesser vacuolar degeneration and hepatic necrosis (Fig.6D and E). LNLP protected the liver tissue against $\mathrm{CCl}_{4}$ toxicity with mild hepatocellular degeneration, less inflammatory cell infiltration and well preserved hepatocytes were observed in most areas and the recovery from degeneration of hepatic cells of LNLP pretreated was comparable to that of standard Silymarin (Fig.6C).
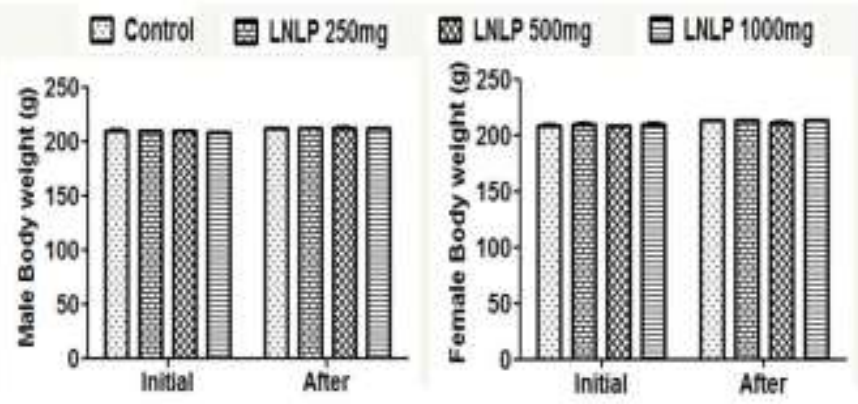

Figure 1. Effect of graded doses of LNLP on the on the mean BW $(\mathrm{g} / 100 \mathrm{~g}$ BW) of male (A) and female (B) albino rats during the acute toxicity study: Values are the mean $\pm \operatorname{SEM}(n=5) ; *, P \leq 0.05$ compared with the experimental and control rats

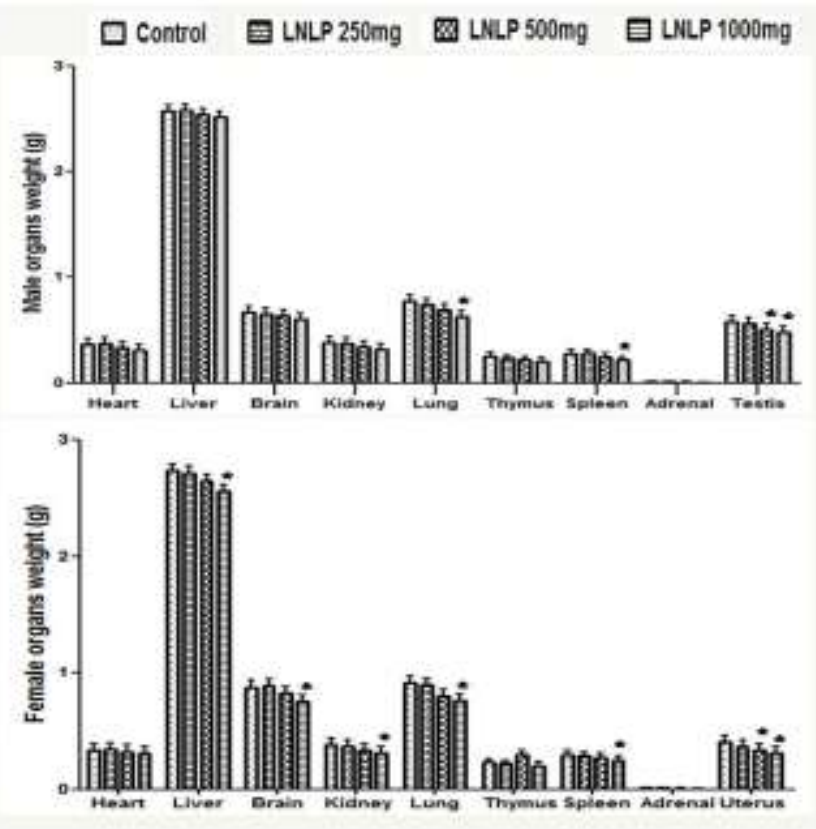

Figure 2. Effect of graded doses of LNLP on the other relative organ weights of male (A) and female (B) albino rats (g/100g BW) during the acute toxicity study: Values are the mean \pm SEM $(n=5)$; $*, P \leq 0.05$ compared with the experimental and control rats.

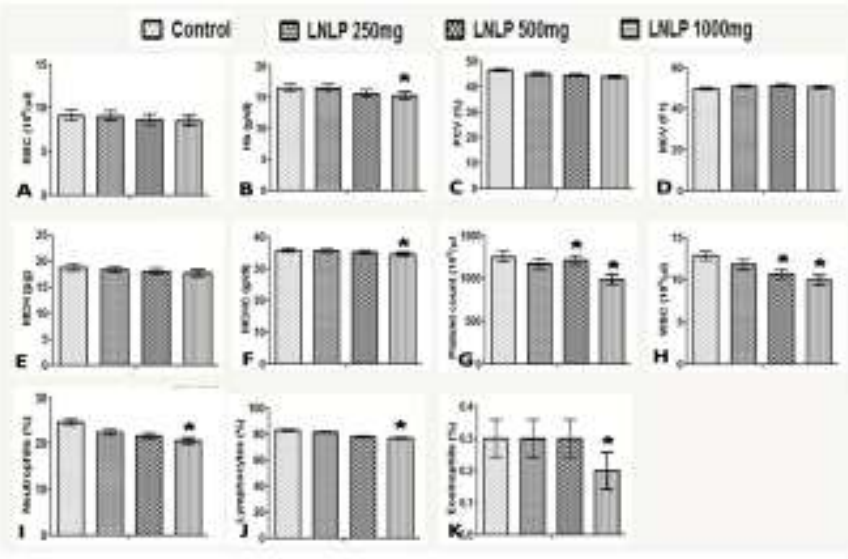

Figure 3. Effect of a graded doses of LNLP on the hematological parameters of male albino rats: (A) RBC; (B) $\mathrm{Hb}$; (C) PCV ; (D) MCV; (E) MCH; (F) MCHC; (G) platelet count; (H) WBC; (I) neutophils; (J) lymphocytes; and $(\mathrm{K})$ eosinophils during the acute toxicity study. Values are the mean $\pm \mathrm{SEM}$ $(n=5) ; *, P \leq 0.05$ compared with the experimental and control rats.

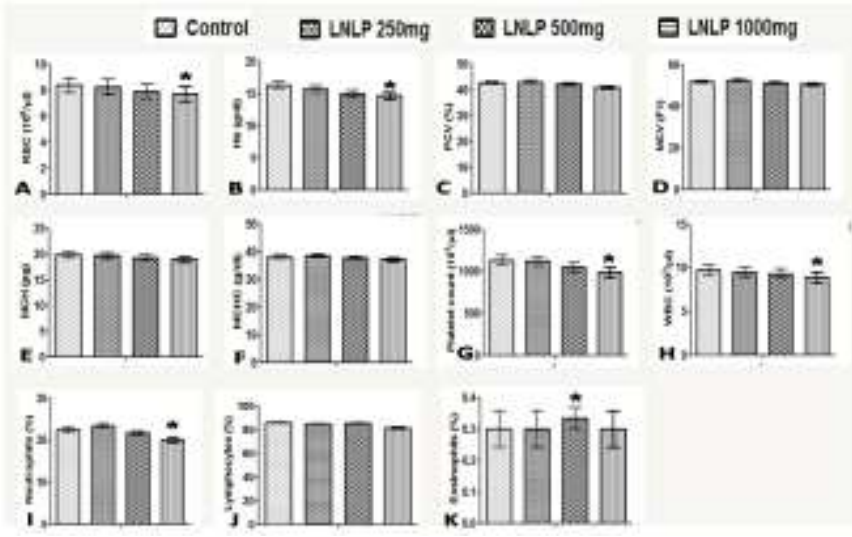

Figure 4. Effect of a graded dose of LNLP on the hematological parameters of female albino rats: (A) RBC; (B) Hb; (C) PCV ; (D) MCV; (E) MCH; (F) MCHC; (G) platelet count; (H) WBC; (I) neutophils; (J) lymphocytes; and (K) eosinophils during the acute toxicity study. Values are the mean $\pm \operatorname{SEM}(n=$ 5 ); * $P \leq 0.05$ compared with the experimental and control rats.

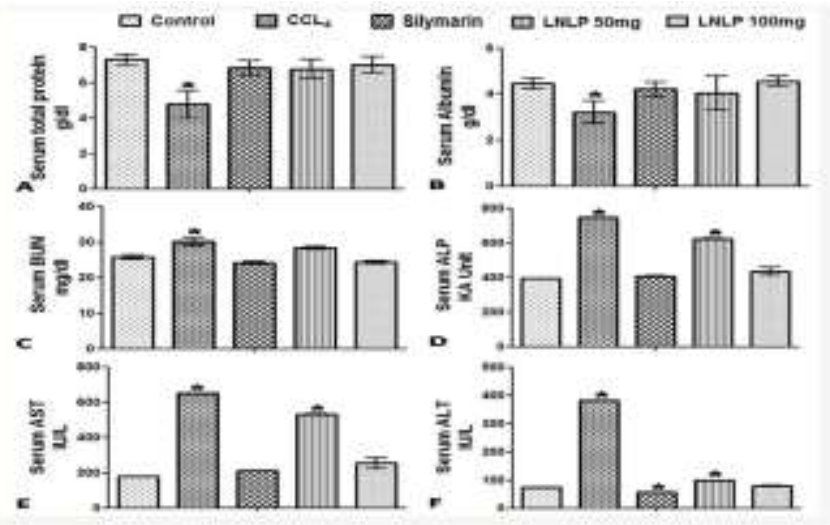

Figure 5. Effects of Silymarin and a graded dose of LNLP on different serum biochemical parameters: (A) total protein; (B) albumin; (C) BUN; (D) ALP; (E) AST; and (F) ALT, in $\mathrm{CCl}_{4}$-induced liver toxicity in male and female albino Wistar rats. Values are the mean $\pm \operatorname{SEM}(n=5) ; *, P \leq 0.05$ compared with the experimental and control rats. 

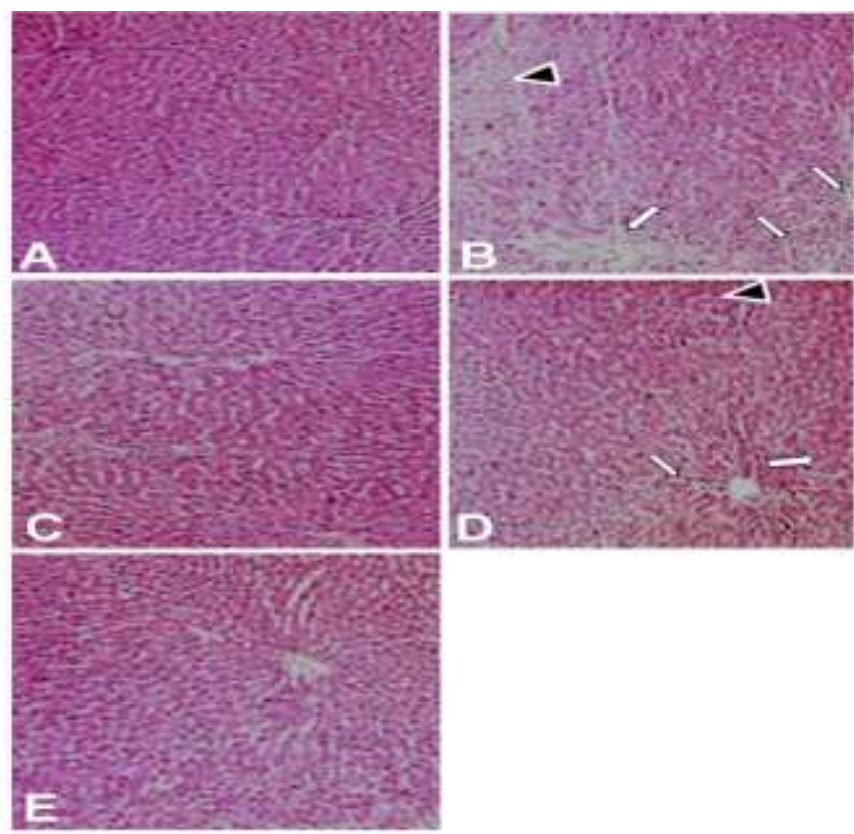

Figure.6. Histopathological changes occurred in the liver after $\mathrm{CCl}_{4}$ intoxication and prevention by pretreatment with graded doses of LNLP and standard Silymarin. (A) Control rats; (B): $\mathrm{CCl}_{4}$ treated group alone $(1 \mathrm{ml} / \mathrm{kg}$ BW) showing damage to hepatocytes with hepatocellular vacuolization, focal hepatic necrosis (arrow head) and congestion of hepatic sinusoids (arrows); (C): Silymarin pretreated group $(100 \mu \mathrm{g} / \mathrm{kg} \mathrm{BW})+\mathrm{CCl}_{4}$; (D): LNLP pretreated group $(50 \mathrm{mg} / \mathrm{kg} \mathrm{BW})+\mathrm{CCl}_{4}(\mathrm{E})$ : LNLP pretreated group $(100 \mathrm{mg}$ $/ \mathrm{kg} \mathrm{BW})+\mathrm{CCl}_{4}$. Note: (C-E) show different degrees of improvement of acute liver injury. $\mathrm{H}$ and $\mathrm{E} \times 100$.

\section{Discussion}

Assessment of organ weights between control and treated groups have conventionally been used in toxicological experiments to foresee toxic consequence of LNLP and no toxicity effect of the substance due to no changes in such parameters, which are often the first signs of toxicity (Carol, 1995). Acute toxicity test was done to establish the adverse consequences of oral administration of LNLP and results indicate no significant changes in general, excluding little alteration in the relative weight of few organs of both either sexes at higher dose level, suggesting this LNLP had no effect on normal growth of rats. Assessment of hematological parameters are not only used to find out the extent of deleterious effect of extracts on the blood of animals, however it can also be used to elucidate blood relating functions of a plant extract or its products (Toyin et al., 2007). In present findings, significant difference in some hematological parameters of both sexes may be indicative of direct or indirect effects of LNLP associated with autoimmune processes (Sjoblad, 1998). The non-toxic nature of LNLP is evident by the absence of mortality for a period of 14 days even when maintained on limit dose indicating this LNLP could be safe up to $1000 \mu \mathrm{g} / \mathrm{kg}$ $\mathrm{BW}$. Any compound or drug with oral $\mathrm{LD}_{50}$ estimates greater than $1000 \mathrm{mg} / \mathrm{kg}$ BW could be considered to be of low toxicity and safe (Clarke and Clarke, 1967).

Liver is the most important key organ in the metabolism, detoxification and secretary functions in the body and it is highly affected primarily by toxic agents that why the above mentioned parameters have been found to be of great importance in the assessment of liver damage (Jamshidzadeh et al., 2005). The preventive action of liver damage by $\mathrm{CCl}_{4}$ has been widely used as an indicator of liver protective activity of drugs/ plant extracts. Studies have been established on pretreatment with extract/herbal formulations of various plants were found to be effectual against $\mathrm{CCl}_{4}$ induced liver damage and had restored the levels of total protein, albumin and serum marker enzymes towards normalization and such effects were comparable with Silymarin standard drug (Dhanasekaran et al., 2009; Srivastava and Shivanandappa, 2010; Ahamed et al., 2010; Patrick-Iwuanyanwu et al., 2011 and Baligar et al., 2014a, b). In this study, $\mathrm{CCl}_{4}$ treated rats exhibited a marked reduction $(\mathrm{P} \leq 0.05)$ in the serum levels of protein and albumin due to the hepatotoxin intoxication. Protein plays a major role in the synthesis of microsomal detoxifying enzymes to detoxify the toxicants (Ramasamy, 1987). It is well indicated by elevated in the levels of BUN, ALP and hepato specific enzymes like AST and ALT in $\mathrm{CCl}_{4}$ induced group compared to normal controls. BUN is also a marker of liver and renal functions, which is used to diagnose acute and chronic diseases related to liver and kidney. A reduction in albumin level has been attributed to massive necrosis of the liver, deterioration of liver function and glycogen impairment of oxidative phosphorylation (Ezzat et al., 1989). Increase in levels of protein and albumin suggests the stabilization of endoplasmic reticulum leading to protein synthesis (Mondal et al., 2005; Sureshkumar and Mishra, 2006). Preventing the induced $\mathrm{CCl}_{4}$ toxicity elevated level of BUN along with decline in the total protein and albumin levels indicating the hepatoprotective nature of LNLP.

$\mathrm{CCl}_{4}$-induced hepatic injuries are generally used models for the screening of hepatic drugs and the degree of hepatic damage is evaluated by the level of released cytoplasmic transaminases (ALT and AST) and alkaline phosphatase (ALP) in circulation (PatrickIwuanyanwu et al., 2011). The capability of hepatoprotective substances to diminish the damage or to preserve the mechanisms of liver function against disturbances of hepatic toxin is an indication of their protective effects (Ranawat et al., 2010). At higher dose level of LNLP, the recovery towards normalization in these two levels was similar to that of standard drug. Considerable increase in the AST, ALT and ALP levels after administration of $\mathrm{CCl}_{4}$ and reduction in these marker enzymes levels towards the normal value by pretreatment with LNLP and Silymarin to $\mathrm{CCl}_{4}$ treated rats is an indicator of the regeneration process of the repair tissue damage caused by $\mathrm{CCl}_{4}$ liver. Increase in serum enzyme activities and the fall in protein and albumin levels caused by $\mathrm{CCl}_{4}$ have been attributed to the damaged structural integrity of the liver and hepatocellular dysfunction (Sallie et al., 1991). The regenerative effects with pretreatment with LNLP can be considered as an appearance of the functional improvement of hepatocytes and restoration of deficient functioning of marker enzymes implicating its cytoprotective role by stabilizing action at the membrane level towards normal liver cell function. Moderate improvement of pathological effects in pretreated LNLP against acute dose of $\mathrm{CCl}_{4}$ treated albino rats, thus it appears that this LNLP play a key role in the reduction of hepatic injury and then preserve the structural integrity of the hepatocellular structures. However, the hepatoprotective mechanisms of LNLP remain to be revealed.

\section{Acknowledgement}

Funding grants from University Grants Commission for research under the program X Plan/KAKA 046/UGC-SWRO and Cumulative Professional Development allowance (CPDA), Indian Institute of Science (IISc) are duly acknowledged.

\section{References}

[1] R.R. Chattopadhyay, S.K. Sarkar, S.Ganguly, R.N. Banerjee, T.K. Basu and A.Mukherjee, "Hepatoprotective activity of Azadirachta indica 
Proc. of the Seventh International Conference On Advances in Applied Science and Environmental Engineering - ASEE 2017. Copyright ( $)$ Institute of Research Engineers and Doctors. All rights reserved.

ISBN: 978-1-63248-125-2 doi: 10.15224/ 978-1-63248-125-2-02

leaves on paracetamol induced hepatic damage in rats". Ind. J. Exp. Biol, 30, 738-740, 1992.

[2] S.Khatkar, S.Sardana, S.Aggarwal and A.Khatkar, "Hepatoprotective effect of the root and stem bark of Azadirachta indica A. Juss. against paracetamol induced liver damage in rats". Int. J. Pharma. Rec.Res, 2, 61-64, 2010.

[3] N.S.Baligar, R.H.Aladakatti, Mukhtar Ahmed and M.B.Hiremath, "Hepatoprotective activity of neem based constituent azadirachtin-A in carbon tetrachloride intoxicated albino rats". Int. J.Pharm. Sci.Res, 5, 3455-3466, 2014

[4] N.S.Baligar, R.H.Aladakatti, Mukhtar Ahmed and M.B.Hiremath, "Hepatoprotective activity of neem based constituent azadirachtin-A in carbon tetrachloride intoxicated albino rats". Can.J.Physiol.Pharmacol, 92, 267-277, 2014.

[5] O.E.C.D, "Acute oral toxicity method". In: OECD guideline for testing of chemicals, No. 404. Organization for Economic Cooperation and Development, Paris, France.1987.

[6] R. Nair V. Shukla and S.Chanda, "Effect of single dose administration of Polyalthia longifolia (Sonn.) Thw. var. pedula leaf on gross behavioral assessment in mice". Ind. Drugs, 46, 116-123, 2009.

[7] H. Theml, H. Diem and T. Haferlach, "Color Atlas of Hematology". Practical Microscopic and Clinical Diagnosis, $2^{\text {nd }}$ ed. Munich, Germany, 7-128, 2004.

[8] H. Matsuda, K. Samukawa and M. Kubo, "Antihepatotoxic activity of Ginsenoside Ro". Planta. Med, 57, 523-526, 1991.

[9] H.Yatzidis, "An improved Biuret reagent". Clin. Chem, 23, 908, 1977.

[10] R.M.Corcoran and S.M. Durnan, "Albumin determination by modified bromcresol green method". Clin. Chem, 23,765-766, 1977.

[11] J.K. Fawcett and J.E. Scott, "A rapid and precise method for the determination of urea". J.Clin. Pathol, 13, 156-159, 1960.

[12] P.R.N. Kind and E.J. King, "Estimation of plasma phosphatase by determination of hydrolysed phenol with amino-antipyrine". J. Clin. Pathol, 7, 322-326, 1954.

[13] S.Reitman and S.Frankel, "A colorimetric method for the determination of serum glutamic oxaloacetic and glutamic pyruvic transaminases". Am. J. Clin. Pathol, 28, 56-63,1957.

[14] A.E. Galigher and E.N. Kozloff, "Essential of Practical Microtechnique" Lea and Febiger, Philadelphia. 77-78, 1971.

[15] S.A. Carol, "Acute, subchronic and chronic toxicology". In: CRC Handbook of Toxicology, Eds. M.J.Derelanko and M.A.Hollinger, USA, CRC Press. 51-104, 1995.

[16] Y.M.Toyin, A.M.Adewumi and O.A.Temidayo, "Hematological evaluation in male albino rats following chronic administration of aqueous extract of Fadogia agrestis stem”. Pharmacog. Magazine, 3, 3438, 2007.

[17] R.D. Sjoblad, "Potential future requirements for immunotoxicology testing of pesticides". Toxicol. Ind. Health, 4, 391-395, 1988.

[18] M.L. Clarke and E.G.C. Clarke, "Veterinary toxicology". London: Bailliere Tindall.1967.

[19] A. Jamshidzadeh, F. Fereidooni, Z. Salehi and H. Niknahad, "Hepatoprotective activity of Gundelia tourenfortii". J. Ethnopharmacol, 101, 233-237, 2005.

[20] M. Dhanasekaran, S. Ignacimuthu and P. Agastian, "Potential hepatoprotective activity of ononitol monohydrate isolated from Cassia tora L. on carbon tetrachloride induced hepatotoxicity in wistar rats". Phytomed, 16, 891-895, 2009.

[21] A. Srivastava and T.Shivanandappa, "Hepatoprotective effect of the root extract of Decalepis hamiltonii against carbon tetrachloride-induced oxidative stress in rats". Food. Chem, 118, 411-417, 2010.

[22] M.B.K. Ahamed, V.Krishna and C.J.Dandin, "In vitro antioxidant and in vivo prophylactic effects of two $\gamma$-lactones isolated from Grewia tiliaefolia against hepatotoxicity in carbon tetrachloride intoxicated rats". Eur. J. Pharmacol, 631, 42-52, 2010.

[23] K.C. Patrick-Iwuanyanwu, M.O. Wegwu and T. Makhmoor, "Hepatoprotective effect of crude methanolic extract and fractions of Ring worm plant Senna alata (L. Roxb) leaves from Nigeria against carbon tetrachloride induced hepatic damage in rats". Euro. J. Exp. Biol, 1,128-138, 2011.

[24] R. Ramasamy, "Effects of sevin on blood free amino acids level of the fish sarotherodon mossambicus". Environ. Ecol, 5, 633-637,1987.

[25] I.E.Ezzat, O.A.I. Salem, M.A. Shousha, and A.E. Abd el-Moneim, "The influence of gamma-irradiation and protein deficiency onsurvival body weight and some blood component in rats". Egypt. J. Biochem, 7, 125$152,1989$.
[26] S.K. Mondal, G.Chakraborty, M. Gupta and U.K. Mazumder, "Hepatoprotective activity of Diospyros malabarica bark in $\mathrm{CCl}_{4}$ intoxicated rats" Eur. Bull.Drug.Res, 13, 25-30, 2005.

[27] S.V. Sureshkumar and S.H.Mishra, "Hepatoprotective effect of extracts from Pergularia daemia Forsk." J.Ethnopharmacol, 107, 164-168, 2006.

[28] L.Ranawat, J,Bhatt and J,Patel, "Hepatoprotective activity of ethanolic extracts of bark of Zanthoxylum armatum $\mathrm{DC}$ in $\mathrm{CCl}_{4}$ induced hepatic damage in rats" J.Ethnopharmacol,127, 777-780, 2010.

[29] R.Sallie, J.M Tredger and R.William, "Drugs and liver" Biopharma. Drug.Dispos, 12, 251-259, 1991.

About Author (s):

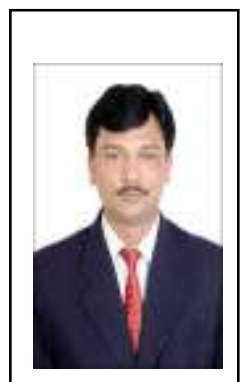

Dr.Ravindranath $\mathrm{H}$ Aladakatti working as Senior Scientific Officer at the Central Animal Facility, Indian Institute of Science (IISc), Bengaluru. He has been selected for the University Research Studentship and received his M.Phil.and Ph.D. from the Karnataka University, subsequently worked as Post Doctoral Fellow at Centre for Human Genetics Lab in Human Genome Project and DBT Fellow in Dept.of MRDG, IISc. His research interests include Mammalian Gamete Biology, Management of Male (In) Fertility by means of Phytotherapy approach, Pharmacognosy and environmental toxicology. He has published several papers in various reputed journals and made several paper presentations at conferences/symposia/workshops. He has been bestowed with Award of Scientist of the Year 2008 from National Environmental Science Academy (NESA), New-Delhi. $\mathrm{He}$ is member of several societies and professional bodies.

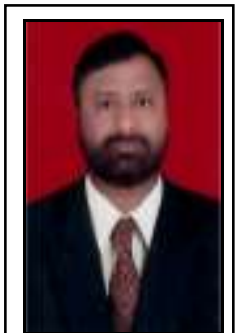

Dr. Mukhtar Ahmed. G. Ghodesawar working as Professor in Department of Zoology at Anjuman Arts, Science and Commerce College, Vijayapura- 586 101, Karnataka, India. He received his Ph.D. from the Karnataka University and involved in different research programs. His research interests include Management of Male (In) Fertility by means of Phytotherapy approach and Pharmacognosy. He is recipient of Bharat Shiksha Ratan Award-2013, Rajiv Gandhi Gold Medal Award-2015, Research Project Grant from the University Grant Commission (UGC), New-Delhi and best paper presentations awards. He is member of several societies, professional bodies and published several articles in reputed National and International journals. 